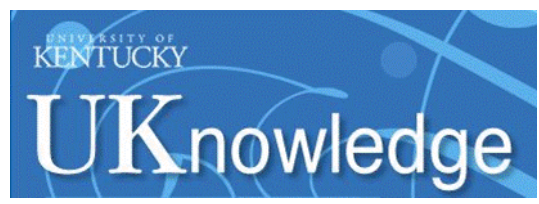

University of Kentucky

UKnowledge

2-17-2017

\title{
Recoverable Stress Induced Two-Way Shape Memory Effect on NiTi Surface Using Laser-Produced Shock Wave
}

\author{
Dovletgeldi Seyitliyev \\ Western Kentucky University \\ Peizhen Li \\ University of Kentucky, peizhen.li@uky.edu \\ Khomidkhodza Kholikov \\ Western Kentucky University \\ Byron Grant \\ Western Kentucky University \\ Zachary Thomas \\ Western Kentucky University
}

See next page for additional authors

Follow this and additional works at: https://uknowledge.uky.edu/me_facpub

Part of the Mechanical Engineering Commons, and the Plasma and Beam Physics Commons

Right click to open a feedback form in a new tab to let us know how this document benefits you.

\section{Repository Citation}

Seyitliyev, Dovletgeldi; Li, Peizhen; Kholikov, Khomidkhodza; Grant, Byron; Thomas, Zachary; Alal, Orhan; Karaca, Haluk E.; and Er, Ali O., "Recoverable Stress Induced Two-Way Shape Memory Effect on NiTi Surface Using Laser-Produced Shock Wave" (2017). Mechanical Engineering Faculty Publications. 40. https://uknowledge.uky.edu/me_facpub/40

This Conference Proceeding is brought to you for free and open access by the Mechanical Engineering at UKnowledge. It has been accepted for inclusion in Mechanical Engineering Faculty Publications by an authorized administrator of UKnowledge. For more information, please contact UKnowledge@lsv.uky.edu. 


\title{
Recoverable Stress Induced Two-Way Shape Memory Effect on NiTi Surface Using Laser-Produced Shock Wave
}

\author{
Digital Object Identifier (DOI) \\ https://doi.org/10.1117/12.2252504
}

\section{Notes/Citation Information}

Published in Proceedings of SPIE, v. 10092, Laser-based Micro- and Nanoprocessing XI, article 100921J, p. 1-5.

Copyright 2017 Society of Photo-Optical Instrumentation Engineers (SPIE). One print or electronic copy may be made for personal use only. Systematic reproduction and distribution, duplication of any material in this paper for a fee or for commercial purposes, or modification of the content of the paper are prohibited.

Dovletgeldi Seyitliyev, Peizhen Li, Khomidkhodza Kholikov, Byron Grant, Zachary Thomas, Orhan Alal, Haluk E. Karaca, Ali O. Er, "Recoverable stress induced two-way shape memory effect on NiTi surface using laser-produced shock wave," Proc. SPIE 10092, Laser-based Micro- and Nanoprocessing XI, 100921J (17 February 2017). DOI: https://doi.org/10.1117/12.2252504

The copyright holder has granted the permission for posting the article here.

\section{Authors}

Dovletgeldi Seyitliyev, Peizhen Li, Khomidkhodza Kholikov, Byron Grant, Zachary Thomas, Orhan Alal, Haluk E. Karaca, and Ali O. Er 


\section{Recoverable stress induced two-way shape memory effect on NiTi surface using laser-produced shock wave}

Dovletgeldi Seyitliyev, Peizhen Li, Khomidkhodza Kholikov, Byron Grant, Zachary Thomas, et al.

Dovletgeldi Seyitliyev, Peizhen Li, Khomidkhodza Kholikov, Byron Grant, Zachary Thomas, Orhan Alal, Haluk E. Karaca, Ali O. Er, "Recoverable stress induced two-way shape memory effect on NiTi surface using laserproduced shock wave," Proc. SPIE 10092, Laser-based Micro- and Nanoprocessing XI, 100921J (17 February 2017); doi: 10.1117/12.2252504 


\title{
Recoverable stress induced two-way shape memory effect on NiTi surface using laser-produced shock wave
}

\author{
Dovletgeldi Seyitliyev ${ }^{\mathrm{a}}$, Peizhen Li $^{\mathrm{b}}$, Khomidkhodza Kholikova ${ }^{\mathrm{a}}$, Byron Grant ${ }^{\mathrm{a}}$, Zachary Thomas ${ }^{\mathrm{a}}$, \\ Orhan Alal ${ }^{\mathrm{a}}$, Haluk E. Karacab ${ }^{\mathrm{b}}$ Ali O. Er ${ }^{\mathrm{a}^{*}}$. \\ aDepartment of Physics and Astronomy, Western Kentucky University, 1906 Collage Heights Blvd., \\ Bowling Green, KY, USA 42101; ' Department of Mechanical Engineering, University of Kentucky, \\ RGAN 210, Lexington, KY USA 40506-0503
}

\begin{abstract}
The surfaces of $\mathrm{Ni}_{50} \mathrm{Ti}_{50}$ shape memory alloys (SMAs) were patterned by laser scribing. This method is more simplistic and efficient than traditional indentation techniques, and has also shown to be an effective method in patterning these materials. Different laser energy densities ranging from $5 \mathrm{~mJ} /$ pulse to $56 \mathrm{~mJ} /$ pulse were used to observe recovery on SMA surface. The temperature dependent heat profiles of the NiTi surfaces after laser scribing at $56 \mathrm{~mJ} /$ pulse show the partiallyrecovered indents, which indicate a "shape memory effect (SME)" Experimental data is in good agreement with theoretical simulation of laser induced shock wave propagation inside NiTi SMAs. Stress wave closely followed the rise time of the laser pulse to its peak values and initial decay. Further investigations are underway to improve the SME such that the indents are recovered to a greater extent.
\end{abstract}

Keywords: laser-shockwave, recovery, shape memory, direct laser ablation

\section{INTRODUCTION}

The development of direct surface patterning has recently experienced intensive efforts. Laser methods has opened a way of fabricating periodic structures directly on polymers, ceramics, metals, and more dimensional surface patterns on variety of components in industry including aerospace, automotive, and microelectronics $[1,2]$. Surface patterning by lasers offers a variety of advantages such as flexibility, cleanliness, precise modification of the surface, remote and contact-free operation, and precise energy deposition [3]. Unlike conventional patterning methods which are slow, expensive, not environment friendly, and suffers from the disadvantages of low reproducibility, laser patterning is inexpensive, environment friendly, very fast with minimal distortion, and doesn't involve any heating or etching process [4].

Shape memory alloys (SMAs) are a unique class of smart materials with the ability to modify their shapes with temperature and stress. SMAs are playing a growing role in supplying key actuation forces and sealing functions in oil and gas, automotive, aerospace and biomedical industries. Their ability to remain elastic under large deformation makes SMAs potential candidates for super-elastic devices in civil structures, and their super elasticity, remarkable corrosion resistance, biological and magnetic resonance compatibility and high bending resistance have already resulted in their implementation in biomedical devices.

Since the discovery of the well-known Shape memory alloys (SMAs), much progress and study has been made both in the scientific understanding and real-life applications due to their unique properties such as shape memory effect (SME) and superelasticity (SE), where they can recover large deformations through reversible phase transformations $[5,6]$. The most well-known shape memory alloys is NiTi since it has good ductility and large transformation strain (10\%) that makes them suitable for many commercial applications such as actuators, sensors, dampers, sealing elements, couplers, biomedical devices and electrical components $[7,8]$. Due to the appropriate low transformation temperatures $\left(<100{ }^{\circ} \mathrm{C}\right)$ and strength $(<700 \mathrm{MPa})$ of the near-equiatomic NiTi alloys, it is instructive to use for laser fabrication in order to see the depth recovery at low temperature range $\left(80-150^{\circ} \mathrm{C}\right)$ which is convenient for low temperature applications.

*ali.er@wku.edu; $\quad$ phone $\quad 1 \quad 270 \quad$ 745-6202; $\quad$ physics.wku.edu/ali.er/

Laser-based Micro- and Nanoprocessing XI, edited by Udo Klotzbach, Kunuhiko Washio, Rainer Kling,

Proc. of SPIE Vol. 10092, 100921J · @ 2017 SPIE · CCC code: 0277-786X/17/\$18 · doi: 10.1117/12.2252504 
In laser-assisted direct imprinting, a high-power laser pulse interacts with materials in a thin layer, it can induce high amplitude plasma pressure ( $>1 \mathrm{GPa}$ ) in a short duration (usually on the order of $10^{-9}$ seconds), creating a strong shock wave, consequently, forming three-dimensional structure. Laser ablation can be categorized into various mechanisms such as photothermal, photochemical, hydrodynamical and exfoliational, and ultrafast laser ablation depending on the pulse width. When an additional transparent overlay is used, enhanced pressure (4-10 times higher) on the material surface could easily be attained and gas breakdown loss is prevented [3]. Later, a method to create protrusions on the surfaces of SMAs was discovered by utilizing reversible depth change observed in SMAs and planarization method [9]. Thermal cycling on SMAs which may be repeated indefinitely, results in a 'bumpy' and a flat surface. The geometry of the protrusion depends on the processing parameters and material properties.

In SMAs, indentation-induced shape memory effect and superelasticity was observed under complex loading conditions [10-12]. Specifically, shallow spherical indents in austenite NiTi specimen can fully recover upon unloading, but indents in martensite only partially recovered while full recovery occurs upon heating to austenite phase. Experimental indentation testing under spherical indenter revealed the "self-healing" effect [13]. A recent study has shown that patterned micro indents can be generated on the surface of NiTi SMA by laser shock assisted direct imprinting and it is much easier and faster than creating surface patterns through indentation techniques [14].

In laser produced shock wave, when the magnitude of the primary shockwave front is above the dynamic yield strength of the material, termed as the Hugoniot Elastic Limit, it plastically deforms the microstructure and creates added dislocations in the material until shockwave attenuates below HEL. It should be noted that while SMAs don't appear to exhibit a Hugoniot elastic limit like other metals, the amount of deformation depends on the pressure.

Although laser shock assisted direct scribing was shown to be possible to create active surfaces [15], the effects of laser parameters as well as material properties on the indent geometry and shape recovery properties has not been investigated in detail. In this study, we report for the first time nearly $20 \%$ recovery from martensitic state of NiTi shape memory alloy by laser shock assisted direct laser imprinting method.

\section{EXPERIMENTAL METHODS}

The nominal composition of $\mathrm{Ni}_{50} \mathrm{Ti}_{50}$ alloys were from NASA (round) and Kellog's Research lab (square). The alloys were firstly electrical-discharge machined to a circular plate with a diameter of $10 \mathrm{~mm}$ and thickness of $1 \mathrm{~mm}$. The surface roughness of round and square samples were reduced to $0.05 \mu \mathrm{m}$ and $0.2 \mu \mathrm{m}$ respectively, in five steps by using Buehler EcoMet 250 Grinder-Polisher with an AutoMet 250 Power head. Differences in final roughness is due to initial differences of samples surface quality. Transformation temperatures were determined by using a Perkin-Elmer Pyris 1 differential scanning calorimeter (DSC). The martensite and austenite start and finish temperatures $\left(\mathrm{M}_{\mathrm{s}}, \mathrm{M}_{\mathrm{f}}, \mathrm{A}_{\mathrm{s}}\right.$, and $\mathrm{A}_{\mathrm{f}}$, respectively) are $78{ }^{\circ} \mathrm{C}, 45^{\circ} \mathrm{C}, 85^{\circ} \mathrm{C}$, and $122{ }^{\circ} \mathrm{C}$ for round samples and $57.5^{\circ} \mathrm{C}, 0.8{ }^{\circ} \mathrm{C}, 28{ }^{\circ} \mathrm{C}$, and $55.8{ }^{\circ} \mathrm{C}$ for square samples.

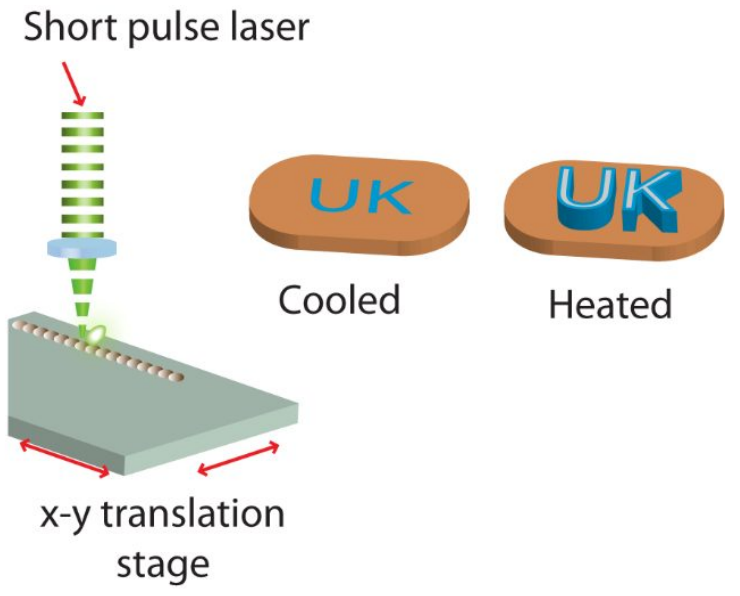

Figure 1. A typical experimental setup for laser scribing of shape memory alloys and SMAs in their cooled and heated state.

A typical experimental setup for laser scribing of shape memory alloys can be seen in Fig. 1. The polished square $\left(10 \mathrm{~mm}^{2}\right.$, $\sim 0.5 \mathrm{~mm}$ thick, $\sim 200 \mathrm{~nm}$ roughness) and round (10 mm diameter, $\sim 1 \mathrm{~mm}$ thick, $\sim 50 \mathrm{~nm}$ roughness) $\mathrm{Ni}_{50} \mathrm{Ti}_{50} \mathrm{SMAs}$ were 
placed under the nanosecond Nd:YAG $(1064 \mathrm{~nm})$ pulsed to generate patterns on the surface. Morphological properties were investigated by light microscope and recovery depth measurements were analyzed by laser profiler (Zygo). An aspheric focusing lens with $5 \mathrm{~cm}$ focal length and convex lens with $20 \mathrm{~cm}$ focal length (Thorlabs) were used. Patterned surface was generated by ablating NiTi surface with the focused laser beam with a repetition rate of $10 \mathrm{~Hz}$ at the energies between 6-56 mJ/pulse with a focused spot size of $\sim 200 \mu \mathrm{m}$ for 1 second when $20 \mathrm{~cm}$ lens is used. In the second part, laser energy was held constant at $50 \mathrm{~mJ} / \mathrm{pulse}$ and $5 \mathrm{~cm}$ of lens was used to focus the laser beam with a spot size of $\sim 100 \mu \mathrm{m}$ on NiTi surface for 2, 4 and 8 seconds.

\section{RESULTS}

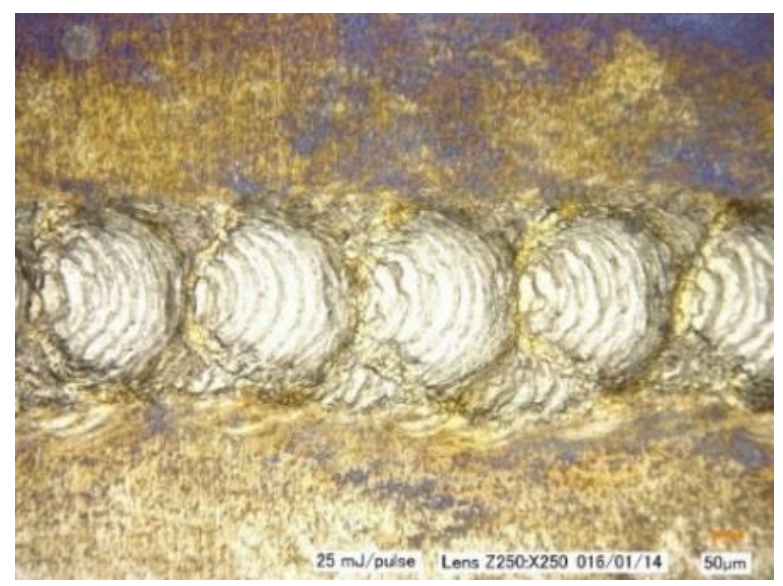

Figure 2. Light microscope image of the surface after the direct laser imprinting at the energy $56 \mathrm{~mJ} / \mathrm{pulse}$.

Fig. 2 shows the sample surface after the patterning by direct laser imprinting at the energy of $56 \mathrm{~mJ} / \mathrm{pulse}$. Round and regular patterns within the distance of spot size $(\sim 200 \mu \mathrm{m})$ was observed. Laser profiler was used for depth analysis. Figure $3 a$ shows the depth images from the laser profiler at the energy of $56 \mathrm{~mJ} /$ pulse and Fig. $3 \mathrm{~b}$ shows the depth recovery measurements at the energies of $12 \mathrm{~mJ} /$ pulse (as a reference) and $56 \mathrm{~mJ} / \mathrm{pulse}$. It can be seen from the Fig. $3 \mathrm{~b}$ that 12 $\mathrm{mJ} /$ pulse did not generate enough stress to have the recovery. However, recovery of $\sim 20 \%$ was successfully obtained at the laser energy of $56 \mathrm{~mJ} / \mathrm{pulse}$ which is the enough energy that generates enough stress to transform the NiTi SMA from martensitic to austenitic state when heated above its $A_{f}$ temperature. This results was achieved by focusing the laser onto the sample using $20 \mathrm{~cm}$ convex lens with a laser spot size of $\sim 200 \mu \mathrm{m}$ for 1 seconds.

\begin{tabular}{|c|c|c|c|c|c|}
\hline Temperature & Laser energy ( $\mathrm{mJ} /$ pulse) & Depth $1(\mu \mathrm{m})$ & Depth $2(\mu \mathrm{m})$ & Depth $3(\mu \mathrm{m})$ & Depth $4(\mu \mathrm{m})$ \\
\hline \multirow{5}{*}{ Room } & 56 & 14.1 & 14.2 & 14.6 & 15.9 \\
\hline & 25 & 11.7 & 12.3 & 12.62 & 13.94 \\
\hline & 18 & 10.71 & 11.34 & 10.94 & 10.2 \\
\hline & 12 & 4.61 & 4.85 & 3.94 & 5.01 \\
\hline & 6 & 0.8 & 1.76 & N/A & N/A \\
\hline \multirow{5}{*}{ High $150^{\circ} \mathrm{C}$} & 56 & 11.95 & 11.45 & 11.98 & 10.7 \\
\hline & 25 & 11.89 & 12.12 & 12.73 & 13.49 \\
\hline & 18 & 10.82 & 11.19 & 10.41 & 10.6 \\
\hline & 12 & 5.5 & 5.57 & 5.56 & 6.24 \\
\hline & 6 & 0.59 & 1.48 & N/A & N/A \\
\hline
\end{tabular}

Table 1. Results from the square sample after irradiating for 1 second with a repetition rate of $10 \mathrm{~Hz}$ at the energies between 6-56 $\mathrm{mJ} / \mathrm{pulse}$

Table 1 summarizes all other results using these parameters and no recovery was observed in NiTi SMA when laser energy is less than $56 \mathrm{~mJ} /$ pulse. Four different points of the sample was used for measurements to decrease the error in measurements and for the better reliability. It is essential to note that the stress that was generated from the laser irradiation 
also depends on the material's optical parameters in addition to the lasers parameters such as wavelength, energy density, repetition rate, pulse duration, spot size on the target and the surface quality.
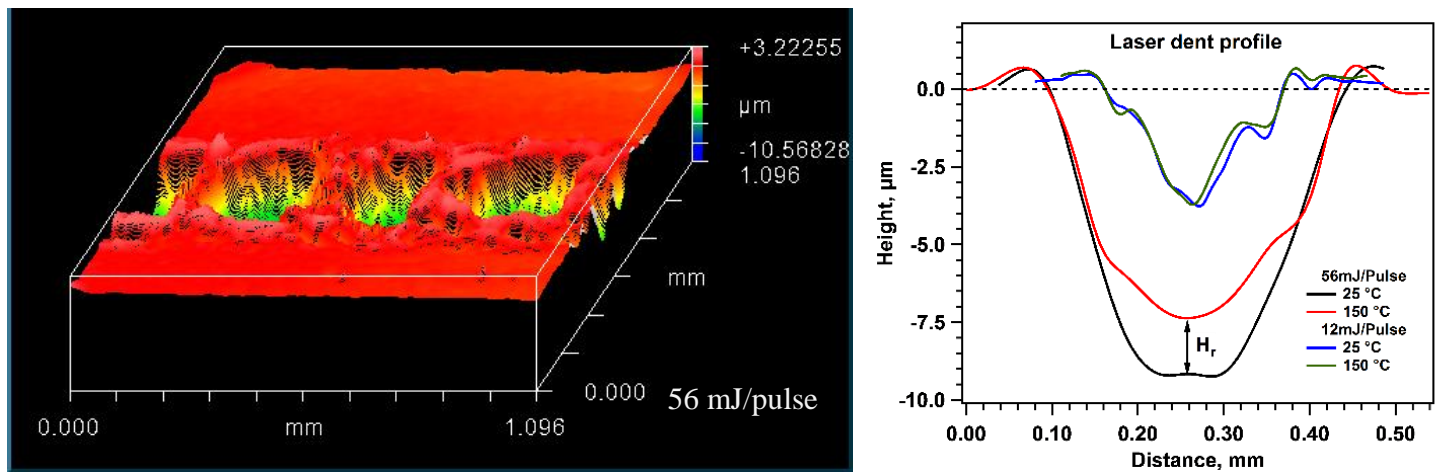

Figure 3. a) Surface profile of NiTi after laser scribing with $56 \mathrm{~mJ} /$ pulse, b) temperature dependent height profiles of laser induced dents created by using two laser energy levels of 56 (black and red) and $12 \mathrm{~mJ} /$ pulse (green and blue), respectively.

Once $56 \mathrm{~mJ} /$ pulse was determined as an enough energy to create stress and recovery, focusing lens $(5 \mathrm{~cm}$ aspheric lens) which focuses the laser to $\sim 100 \mu \mathrm{m}$ spot size on the round (10mm diameter) and thicker ( 1 $1 \mathrm{~mm})$ NiTi SMA was used to understand intensity effect.

\begin{tabular}{|c|c|c|c|}
\hline Time of irradiation (s) & Temperature & Laser energy (mJ/pulse) & Depth $(\mu \mathrm{m})$ \\
\hline 1 & & & 23.13 \\
\hline 2 & \multirow{3}{*}{ Room } & 50 & 32.34 \\
\hline 4 & & & 25.8 \\
\hline 8 & & & 40.52 \\
\hline 1 & & 50 & 22.95 \\
\hline 2 & High $150^{\circ} \mathrm{C}$ & & 27.97 \\
\hline 4 & & & 22.06 \\
\hline 8 & & & 37.64 \\
\hline
\end{tabular}

Table 2. Summary of the results from round NiTi sample at the energy of $50 \mathrm{~mJ} /$ pulse for different irradiation times.

Table 2 shows that recovery of SMA can be obtained when $50 \mathrm{~mJ} /$ pulse for 2 second was used. The recovery for one second ablation was negligible. The recovery ratio was $\sim 14 \%$ for 2 seconds, $\sim 15 \%$ for 4 seconds, and $\sim 7 \%$ for 8 seconds. It is obvious that recovery decreases when duration increases to 8 seconds.

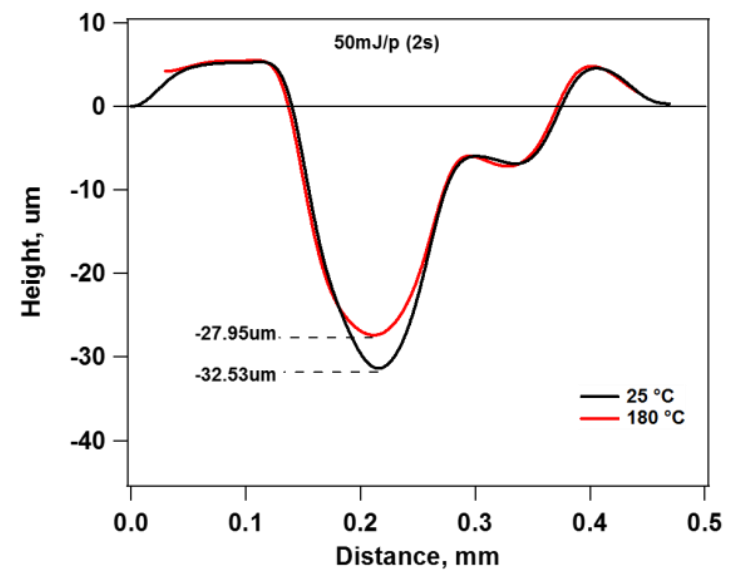

Figure 4. The recovery of NiTi SMA when $50 \mathrm{~mJ} /$ pulse is used for 2 seconds. 
This indicates that optimizing the laser energy density and wavelength is important since an applied stress above a certain level may cause a decrease in shape memory effect $[16,17]$. Figure 4 summarizes these results and shows laser pulses that was irradiated for 2 seconds at $50 \mathrm{~mJ} /$ pulse with a repetition rate of $10 \mathrm{~Hz}$ and spot size of $\sim 100 \mu \mathrm{m}$ generate enough stress on thicker round NiTi samples to get $\sim 15 \%$ recovery. This change could be due to the difference in treatment methods of two samples since they both have different transformation temperatures. So, they have different mechanical behavior and a round NiTi sample needed more stress to get depth recovery.

\section{CONCLUSION}

Laser scribing was shown to be effective method to observe shape memory effect. The recovery of indents generated by laser scribing of the NiTi shape memory alloy at different conditions was reported. The laser energy density of 56 $\mathrm{mJ} /$ pulse with repetition rate of $10 \mathrm{~Hz}$ for one second irradiation was found to create enough stress and subsequent recovery. It was also noticed that certain laser energy density is required for NiTi SMA recover when sample was irradiated for 2 seconds. Two different NiTi SMA with different phase temperatures was used. This difference was related to the difference in treatment method of two NiTi samples, thus each sample has different mechanical behavior such as a need of different minimum stress to change NiTi SMA's phase which is achieved by different laser properties. In summary, no heating or etching is required in this technique. It is relatively easy to have scalable product and expected to be a competitive technique for high technology applications. 